\section{GUIDELINE FOR THE DIAGNOSIS AND TREATMENT OF CHRONIC PANCREATITIS}

\author{
1. Diagnosis and medical treatment \\ 1.1 Background \\ 1.2 Diagnosis \\ 1.2.1 Clinical manifestations \\ 1.2.2 Special investigations \\ 1.3 Aetiology \\ 1.4 Medical treatment \\ 1.4.1 Behaviour modification \\ 1.4.2 Treatment of abdominal pain \\ 1.4.3 Treatment of pancreatic exocrine insufficiency \\ 1.4.4 Detection and treatment of endocrine insufficiency \\ 1.4.5 Nutrition \\ 1.4.6 Screening for pancreatic adenocarcinoma \\ 1.4.7 Autoimmune chronic pancreatitis
}

2. Interventional procedures

2.1 Management of pain in uncomplicated disease

2.1.1 Endoscopic treatment

2.1.2 Neurolysis

2.1.3 Surgery

2.2 Complications in $\mathrm{CP}$

2.2.1 Pseudocysts (pancreatic fluid collections) and ascites

2.2.2 Complications associated with pseudocysts

2.2.3 Duodenal obstruction

2.2.4 Bile duct obstruction

3. Summary and conclusion

Addendum A. Rosemont criteria

Addendum B. EUS diagnosis of chronic pancreatitis

References

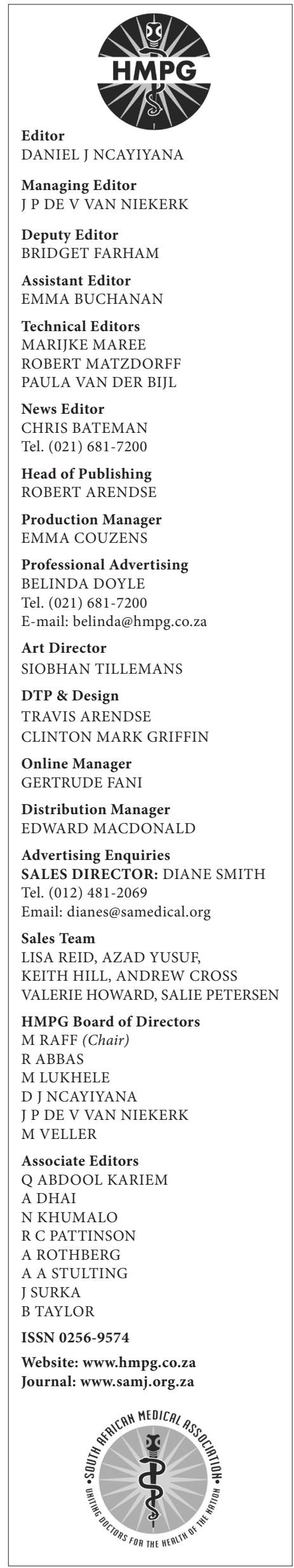




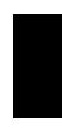




\title{
Guideline for the diagnosis and treatment of chronic pancreatitis
}

\author{
P C Bornman, J F Botha, J M Ramos, M D Smith, S van der Merwe, G A Watermeyer, C C M Ziady
}

Background. Chronic pancreatitis (CP) is defined as a continuing inflammatory disease of the pancreas characterised by irreversible morphological changes, often associated with pain and with the loss of exocrine and/or endocrine function that may be clinically relevant. Alcohol is the predominant cause of $\mathrm{CP}$ in the western world and is particularly prevalent in South Africa, especially in the indigent patient. CP ranks high among intractable diseases of the gastrointestinal tract. The tendency for substance abuse in the alcohol-induced group poses major psychological and socioeconomic problems.

Objective. $\mathrm{CP}$ is a disease with significant clinical and pathological heterogeneity. Level 1 evidence to support definitive guidelines for diagnosis, medical management and interventional therapy is lacking. Despite this paucity of robust scientific evidence, it is important to provide some assistance based on the best available evidence as to the current standard of care for CP in the South African context; this will aid all involved in the management of the disease, and includes clinicians, health care managers and funders. Scope. The guidelines were developed as recommendations addressing the diagnosis, medical management and interventions, both endoscopic and surgical, for the management of a very complex and heterogeneous disease of the pancreas. The recommendations are particularly relevant in the South African context where the predominant patho-aetiological agents are alcohol-associated with smoking.

Recommendations. The guidelines provide clear recommendations regarding the diagnostic modalities available, both imaging (which includes MRI and endoscopic ultrasound (EUS)) and pancreatic function tests. The section on medical management makes recommendations on the use of analgesics, enzyme replacement and other therapeutic options in the non-interventional management of the majority of patients with $\mathrm{CP}$. The section on interventional procedures identifies the indications and options available for the interventional management of both uncomplicated and complicated $\mathrm{CP}$. The role of endoscopic and surgical modalities is defined, but it is in this context especially that the best available evidence, combined with the experience of the group, influenced the recommendations put forward. Owing to the lack of evidence and the complexity of the disease, it is recommended that, where possible, CP is managed in the context of a multidisciplinary team.

Validation. The guidelines are based on best practice principles determined by the available evidence and the opinions of the group, which comprised 7 medical and surgical gastroenterologists with significant experience in dealing with patients with chronic pancreatitis in the South African context. The group convened between May 2009 and August 2010 under the auspices of the Hepato-Pancreatico-Biliary Association of South Africa (HPBASA) and the South African Gastroenterology Society (SAGES), and the guidelines are the result of broad consensus within this group. The draft was presented to other experts in this field of endeavour to ensure broader participation and consensus.

Plans for guideline revision. HPBASA and SAGES will publish a revised modification of the recommendations when new levels 1 and 2 evidence data are published.

S Afr Med J 2010; 100: 845-860.
Department of Surgery, University of Cape Town

P C Bornman, FRCS (Ed), FCS (SA), MMed (Surg), FRCS (Glasg)

Physician/Gastroenterologist in private practice, Sandton Medi-Clinic, Johannesburg J F Botha, MB ChB, FCP (SA)

Department of Surgery, University of the Witwatersrand, Johannesburg J M Ramos, MB BCh, FCS (SA)

Department of General Surgery, Baragwanath Hospital and University of the Witwatersrand

M D Smith, MB BCh, FCS (SA) (Surg Gastroenterology)

Department of Immunology, University of Pretoria

S van der Merwe, MB ChB, MSc, MMed (Int Med), PhD

Division of Gastroenterology, Department of Medicine, Groote Schuur Hospital and University of Cape Town

GA Watermeyer, MB ChB, FCP (SA), Cert Gastroenterology (SA)

Physician/gastroenterologist in private practice, Pretoria

C C M Ziady, MMed (Int) UP

\section{Diagnosis and medical management 1.1 Background}

Chronic pancreatitis (CP) is defined as a continuing inflammatory disease of the pancreas characterised by irreversible morphological changes, often associated with pain and with the loss of exocrine and/or endocrine function which may be clinically relevant. ${ }^{1}$ Alcohol is the predominant cause of $\mathrm{CP}$ in the Western world, and is particularly prevalent in South Africa ${ }^{2}$ (Table I). Changing patterns of alcohol consumption and the availability of more sensitive diagnostic tests have led to the conclusion that $\mathrm{CP}$ is even more prevalent than previously suspected. ${ }^{3}$

Table I. Aetiology of CP

\begin{tabular}{l}
\hline Alcohol ${ }^{*}$ \\
Idiopathic \\
Tropical \\
Obstruction \\
Autoimmune \\
Miscellaneous \\
${ }^{*}$ May be up to $80 \%$ in South Africa ${ }^{2}$ \\
\hline
\end{tabular}


The mechanism by which alcohol induces $\mathrm{CP}$ remains uncertain, but there is increasing evidence that damage to the pancreatic acinar cells occurs through the transient formation of fatty acid ethanol esters (FAEEs) which then leads to the so-called 'necrosisinflammation-fibrosis' sequence which may be self-perpetuating. ${ }^{4}$ The entire pancreas is usually involved but, in about a third of cases, there is a distinct inflammatory mass in the head which often causes biliary and or duodenal obstruction. While in most cases there is progressive pancreatic duct dilatation associated with strictures, there is also a distinct subgroup with small duct disease associated with dense sclerosis. Pancreatic stones in the calcific form of the disease are the result of decreased bicarbonate and water secretion on the one hand, and increased protein and calcium secretion with precipitation into the pancreatic duct system, on the other.

$\mathrm{CP}$ ranks high among intractable diseases of the gastrointestinal tract. The tendency to substance abuse in the alcohol-induced group poses major psychological and socio-economic problems. Two clinical groups are distinguished in the idiopathic and alcohol CP groups, namely (i) a mild form presenting with intermittent attacks and pain-free intervals, and (ii) those with severe disease. ${ }^{5,6}$ The former usually responds well to conservative treatment and tends to improve with time (so-called burn-out syndrome), while the latter is progressive and often comes to surgery for intractable pain with or without complications. The pathogenesis of pain remains an enigma, but there is general consensus that many factors are involved and that these may vary at different stages of the disease.

\subsection{Diagnosis}

Although histology remains the gold standard against which all diagnostic approaches are judged, it is not practical in the clinical setting. Diagnosis currently depends on identifying clinical and morphological features which characterise the final common pathologic pathway of a variety of pancreatic disorders.

\subsubsection{Clinical manifestations}

The primary clinical manifestations of $\mathrm{CP}$ are abdominal pain and pancreatic insufficiency, but patients may also present with the consequences of a complication.

\section{Abdominal pain}

The pain is typically epigastric in location, often radiates to the back, is frequently worse after meals and may be relieved by sitting upright or leaning forward. Pain is usually but not invariably present; in one series, $20 \%$ of patients with CP presented with pancreatic exocrine or endocrine insufficiency, but no pain. ${ }^{5}$

\section{Pancreatic exocrine insufficiency}

Clinically significant fat and protein deficiencies do not occur until over $90 \%$ of pancreatic function is lost. ${ }^{7}$ The clinical manifestations of fat malabsorption are steatorrhoea and flatulence. Malabsorption of fat-soluble vitamins and vitamin B12 may also occur, but clinically symptomatic vitamin deficiencies are rare. ${ }^{8}$

\section{Pancreatic endocrine insufficiency}

Overt diabetes mellitus (DM) typically occurs late in the course of the disease. A family history of type 1 or type $2 \mathrm{DM}$, early pancreatic calcification and distal pancreatectomy increases the risk of developing DM. ${ }^{9}$

Most patients with DM secondary to $\mathrm{CP}$ require insulin. Owing to the loss of glucagon-producing a-cells, such patients are at increased risk of spontaneous and treatment-related hypoglycaemia.

\section{Complications}

Patients may occasionally present with complications of $\mathrm{CP}$, such as duodenal obstruction, bile duct obstruction, pancreatic pseudocyst, pseudo-aneurysm, splenic vein thrombosis, pancreatic ascites, pleural effusion and pancreatic cancer. ${ }^{10}$

\section{Recommendation}

$\mathrm{CP}$ is more prevalent than previously suspected; unexplained abdominal pain, a history suggestive of maldigestion and DM represent end-stage, long-standing disease and should raise the possibility of the diagnosis.

\subsubsection{Special investigations}

$\mathrm{CP}$ represents a spectrum, ranging from end-stage disease with pronounced ductal and parenchymal changes, to mild disease requiring a combination of sophisticated imaging and functional studies to establish a diagnosis. The diagnosis can be made by morphologic criteria alone, or by a combination of morphologic and functional criteria. Pancreatic function tests (PFTs) alone do not distinguish CP from pancreatic insufficiency without CP.

\section{Imaging studies}

Despite the availability of numerous imaging modalities, early CP remains difficult to diagnose. The choice of imaging studies should be based on:

- the available technology

- the available skills

- invasive nature of the investigation.

The choice of modality must involve the above factors. These guidelines are based on the best available evidence and best practice with respect to the role of the different diagnostic modalities.

\section{$\mathrm{X}$-rays of the abdomen}

Plain films reveal pancreatic calcification in only $30 \%$ of patients with CP. Pancreatic calcification is most common in alcoholic $\mathrm{CP}$ and rare in idiopathic pancreatitis.

\section{Ultrasonography}

Transabdominal ultrasonography (TUS) lacks sensitivity and specificity and is of limited value in diagnosing CP. Its main value is to identify other causes of abdominal pain.

\section{Computerised tomography (CT)}

CT has a sensitivity of $75-90 \%$ and a specificity of $85 \%^{11-13}$ and is currently the screening test of choice. The past decade has seen major advances in CT technology; currently, multi-detector CT (MDCT) should be utilised.

$\mathrm{CT}$ findings suggestive of $\mathrm{CP}$ are gland atrophy, dilation of the main pancreatic duct (PD), ductal calculi, intra- or peripancreatic cysts, thickening of the peripancreatic fascia and splenic vein thrombosis. Focal or diffuse enlargement of the pancreas is occasionally seen, and intra-ductal papillary mucinous neoplasm (IPMN) should always be considered in the differential diagnosis. A hypo-dense mass in the head of the pancreas may simulate a carcinoma. Other CT findings suggestive of $\mathrm{CP}$ include heterogenous enhancement of the pancreas and the presence of a mass. Hypo-enhancement is indicative of fibrosis, whereas iso-enhancement suggests the absence of fibrosis.

\section{Endoscopic ultrasound (EUS)}

EUS is increasingly being used to diagnose CP. Four parenchymal criteria (hyperechoic foci, hyperechoic strands, hypoechoic lobules, 
cysts) and 5 ductal criteria (dilated main pancreatic duct, dilated side branches, main duct irregularity, hyperechoic duct margins, and stone) are generally accepted to be indicative of $\mathrm{CP}^{14}$

However, published studies have been difficult to compare because of variations in the threshold and criteria required to diagnose CP. ${ }^{14-}$ ${ }^{19}$ Interpretation is further complicated by the absence of a true gold standard, inter-observer variability and the lack of standardised terminology. The publication of minimum standard terminology $(\mathrm{MST})^{20}$ has been an advance, but there is still controversy on the definition of criteria.

A recent consensus conference on the EUS criteria for a diagnosis of CP led to the publication of the so-called Rosemont Criteria ${ }^{21}$ which stratify $\mathrm{CP}$ into 4 groups consistent with $\mathrm{CP}$, suggestive of $\mathrm{CP}$, indeterminate for $\mathrm{CP}$, and (lastly) normal. The criteria were ranked and weighted and, although not yet validated, are likely to improve particularly specificity ${ }^{21}$ (See Addendum B).

\section{MRI}

MRI changes suggestive of $\mathrm{CP}$ are loss of signal intensity on fatsuppressed T1WI and diminished contrast enhancement. MRCP can delineate fluid-filled structures such as the main pancreatic duct and pseudocyst with good accuracy. As side branches are visualised in only $10-25 \%$ of cases, ${ }^{22,23}$ it is of limited diagnostic value in patients with early CP. At present, MRCP does not have the sensitivity and specificity of ERCP and therefore does not have a central role in assessing the pancreatic duct.

Secretin-enhanced MRCP has been shown to be very sensitive ${ }^{24}$ and may be valuable in the very small group of patients in whom the above modalities have failed to confirm the suspected diagnosis of CP. However, secretin may not be readily available in South Africa.

\section{Table II. Cambridge Classification of $\mathrm{CP}^{25}$}

\begin{tabular}{lll}
\hline Group & Terminology & Findings \\
0 & Normal & Whole gland without abnormal feature \\
& Equivocal & $<3$ abnormal branches \\
1 & Mild & $>3$ abnormal branches \\
2 & Moderate & Abnormal main duct and branches \\
3 & Marked & As above with one or more of the \\
& & following: \\
& & - large cavities $(>1 \mathrm{~cm})$ \\
& & - intraductal filling defects or calculi \\
& & ductal obstruction or strictures \\
& & - gross irregularity \\
& & \\
& &
\end{tabular}

Endoscopic retrograde pancreatography (ERP)

ERP is still valuable in the diagnosis of early CP because it accurately demonstrates the ductal changes as defined by the Cambridge criteria $^{25}$ (Table II). This can be especially valuable when EUS is not available, or the results of the MRCP are equivocal.

Pancreatic function tests (PFTs)

PFTs have limited utility in the diagnosis of CP because of a lack of availability, poor patient tolerance and uncertain validation of the test results. Furthermore, they do not distinguish $\mathrm{CP}$ from pancreatic insufficiency without CP. PFTs are of value in diagnosing pancreatic insufficiency, in evaluating patients with $\mathrm{CP}$ and in providing a basis for rational treatment.

\section{Direct PFTs}

Direct PFTs involve stimulation of the pancreas by means of a meal or hormonal secretagogues, and subsequent collection and analysis of the duodenal fluid. The secretin test measures the ability of the ductal cells to produce bicarbonate, and the cholecystokinin (CCK) tests the ability of the acinar cells to secrete digestive enzymes. The secretin-CCK test provides simultaneous assessment of ductal and acinar secretory capacity. The Lundh test duodenal radiograpic tube placement and sampling after a test meal is too complex and not consistently reproducible to be of value as a clinical test.

\section{Indirect PFTs}

Indirect PFTs measure the consequences of pancreatic exocrine insufficiency and are more widely available than direct PFTs. However, they are less sensitive ,and their main utility is the diagnosis of advanced pancreatic exocrine insufficiency.

\section{Faecal fat}

Quantitative measurement of faecal fat requires a high-fat diet, lack of exogenous enzymes and a $72-\mathrm{hr}$ collection of stool, and is only sensitive for the diagnosis of advanced pancreatic insufficiency. ${ }^{26}$ Stool for acid steatocrit is an attractive alternative to this cumbersome test, as it not only compares favourably in terms of sensitivity and specificity, but is also inexpensive. ${ }^{27}$

\section{Faecal chymotrypsin and elastase-1}

Chymotrypsin and elastase-1 remain relatively stable during transit through the gastrointestinal tract. Measurement is easy and relatively inexpensive, but these tests lack sensitivity for mild to moderate pancreatic exocrine insufficiency and specificity in several nonpancreatic gastrointestinal disorders. ${ }^{28,29}$

\section{Pancreolauryl test (PLT)}

The PLT test involves the ingestion of fluorescein dilaurate and measurement of fluorescein in either serum or a 24-hr urine collection. As with other indirect tests, several non-pancreatic gastrointestinal disorders may reduce specificity.

\section{Breath test}

The breath test involves the oral administration of a ${ }^{13} \mathrm{C}$-labelled substrate which is hydrolysed within the bowel lumen in proportion to the pancreatic lipase activity. Exhaled ${ }^{13} \mathrm{CO}_{2}$ is measured by mass spectrometry or infrared analysis but, as with other indirect tests, it lacks sensitivity and specificity.

\section{Recommendations}

- The diagnosis of CP can be made by morphologic criteria alone, or by a combination of morphologic and functional criteria; however, despite the availability of numerous imaging modalities, early CP remains difficult to diagnose.

- X-rays of the abdomen and TUS have poor sensitivities and are not recommended for screening purposes. CT, as well as MRCP, and increasingly EUS, have become the screening methods of choice. There is still a role for ERP. One or all of these investigations may be required to confirm the diagnosis.

- PFTs do not distinguish CP from pancreatic insufficiency without $\mathrm{CP}$ and have a limited role in the diagnosis of $\mathrm{CP}$. 


\subsection{Aetiology}

Despite numerous attempts, the ideal disease classification system for $\mathrm{CP}$ remains elusive. One such classification is The M-ANNHEIM multiple-risk factor classification of $\mathrm{CP}^{30}$

\section{Pancreatitis with multiple-risk factors Alcohol consumption}

Alcohol accounts for $60-70 \%$ of CP cases in the Western world. The daily alcohol consumption at which persons are at risk of developing $\mathrm{CP}$ has not been established, but is estimated to be $60-80 \mathrm{ml} /$ day. Gender and genetic and other co-factors may play pivotal roles, and the term 'alcoholic pancreatitis' therefore does not necessarily imply chronic alcoholism or harmful patterns of alcohol use. Cigarette smoking appears to increase the risk as well as disease progression of CP.

There are several tools that may aid in identifying individuals with harmful patterns of alcohol consumption. The Alcohol Use Disorders Identification Test (AUDIT) $)^{31}$ provides a reliable assessment, but requires the participant to convert traditional measures into standard drinks. The Paddington Alcohol Test (PAT) ${ }^{32}$ (Table III) can be completed rapidly and compares well with AUDIT.

\section{Table III. Paddington Alcohol Test (PAT)}

1. Do you drink alcohol?

Yes - go to 2 .

No

2. What is the most you drink in any one day?

(Pub measures shown in brackets)

$\begin{array}{lllll}\text { Beer/lager/cider } & \ldots \ldots & \text { Pints (2) } & \ldots \ldots & \text { Cans }(1.5) \\ \text { Strong beer/lager/cider } & \ldots \ldots & \text { Pints (5) } & \ldots \ldots & \text { Cans }(4) \\ \text { Wine } & \ldots \ldots & \text { Glasses (1.5) } & \ldots \ldots & \text { Bottles (9) } \\ \text { Fortified wine } & \ldots \ldots & \text { Glasses (1) } & \ldots \ldots & \text { Bottles (12) } \\ \text { Spirits } & \ldots \ldots & \text { Singles (1) } & \ldots \ldots & \text { Bottles (30) }\end{array}$

\section{Total}

3. If this is more than 8 units per day for a man and 6 units per day for a woman, does this happen:

- once a week or more $=\mathrm{PAT}+\mathrm{ve}$

- or, if less frequent:

- at least once a month $=$ PAT +ve

- less than once a month $=$ PAT - ve (trumped by 4$)$

4. Do you feel your current attendance is related to alcohol?

Yes $=$ PAT + ve

$\mathrm{No}=\mathrm{PAT}-\mathrm{ve}$

\section{Nicotine consumption}

The odds ratio for smokers developing $\mathrm{CP}$, compared with nonsmokers developing $\mathrm{CP}$, ranges from 7.8 - 17.3, and the risk increases with the amount of tobacco smoked. Therefore, tobacco smoking should be considered an independent risk factor for the development of $\mathrm{CP}^{33,34}$

\section{Nutritional factors}

The relationship between protein calorie malnutrition, hypertriglyceridaemia and other hyperlipidaemias and CP remains controversial.

\section{Hereditary factors}

Hereditary factors are believed to play a role in hereditary pancreatitis, familial pancreatitis, early-onset idiopathic pancreatitis, late-onset idiopathic pancreatitis and tropical pancreatitis. Mutations in the gene coding for cationic trypsinogen cause hereditary pancreatitis. ${ }^{35}$ Affected individuals usually develop symptoms before the age of 20 years and are at markedly increased risk of developing pancreatic adenocarcinoma.

Mutations in the genes coding for cystic fibrosis trans-membrane conductance regulator (CFTR) $)^{36}$ and pancreatic secretory trypsin inhibitor (PSTI or SPINK1) ${ }^{37}$ have been identified in patients with idiopathic $\mathrm{CP}$

\section{Efferent duct factors}

Entities associated with obstructive CP include trauma, calculi, pseudocysts and tumours. It is controversial whether pancreas divisum and sphincter of Oddi dysfunction cause CP.

\section{Immunological factors}

Autoimmune pancreatitis may be seen in isolation or in association with Sjøgren syndrome, inflammatory bowel disease and a number of other auto-immune disorders.

Serological findings of value in diagnosing autoimmune pancreatitis are hypergamma-globulinaemia, elevated IgG, elevated IgG4 and the presence of several auto-antibodies (anti-nuclear antibodies, antilactoferrin antibodies, anti-carbonic anhydrase 11 antibodies and anti-smooth muscle antibodies). ${ }^{38}$ It is an important condition to recognise as the lesion responds to treatment with corticosteroids

\section{Miscellaneous and rare metabolic factors}

Chronic renal failure ${ }^{39}$ and hyperparathyroidism ${ }^{40}$ are recognised causes of $\mathrm{CP}$, whereas the exact role of medications and toxins remains to be established.

\section{Recommendations}

- A detailed history is of crucial importance as it may provide the clue to the aetiology. Special attention should be paid to occupation and possible exposure to toxins, nutrition, and alcohol and tobacco consumption. The use of a validated tool aimed at identifying harmful drinking patterns is encouraged.

- Renal disease and hyperparathyroidism should be considered in the differential diagnosis and a history of auto-immune disease should raise the possibility of auto-immune pancreatitis.

- A detailed family history should be obtained and, if an inherited disorder is suspected, the assistance of a genetic counsellor sought.

\subsection{Medical treatment}

\section{Goals}

Medical management of the patient with CP should focus on relieving symptoms and preventing the development of complications. There are 6 main goals that should be attained:

1. cessation of alcohol consumption and cigarette smoking

2. determine the cause of abdominal pain and attempt to relieve it

3. treat pancreatic exocrine insufficiency

4. detect and treat endocrine insufficiency early, before complications set in 
5. nutritional support

6. screening for pancreatic adenocarcinoma in cases of hereditary pancreatitis.

\subsubsection{Behaviour modification}

Complete cessation of alcohol ingestion is recommended to reduce future morbidity and mortality. Furthermore, abstinence can in some cases lead to symptomatic improvement and pain relief, while ongoing alcohol ingestion contributes substantially to disease progression. ${ }^{41}$ However, cessation of alcohol does not necessarily halt disease progression. Alcohol cessation is best achieved by enlisting the help of an alcohol dependency counsellor or psychologist. Patients also need to be advised to stop smoking as this is a strong and independent risk factor for chronic alcoholic pancreatitis. ${ }^{42}$

\section{Recommendations}

All patients with CP should be advised to stop smoking and to abstain from alcohol consumption.

\subsubsection{Treatment of abdominal pain}

Pain is the most common and most significant symptom of CP. The mechanism of pain is poorly understood and probably multi-factorial. Several factors may exacerbate pain, and diagnostic tests may be necessary to search for these to institute appropriate treatment which may entail surgical or endoscopic intervention. ${ }^{43}$ Factors include pseudocyst formation, duodenal stenosis, biliary tract stricture, pancreatic cancer and peptic ulcer disease. If these are excluded, medical therapy is initiated using a sequential (step-up) approach. Although the pain of $\mathrm{CP}$ may 'burn out' over time, particularly in alcohol-related disease, the duration over which this occurs is unpredictable. ${ }^{44}$ Initial therapy consists of simple, non-narcotic episodic analgesia in the form of paracetomol or non-steroidal antiinflammatory drugs (NSAIDs), together with a low-fat diet.

Patients who fail to respond could receive a 6-week trial of high-dose pancreatic enzymes (in uncoated tablet form). ${ }^{43-46}$ The recommended dose is equivalent to Viokase 16; 12 tablets per day, in divided doses with meals and snacks. However, the evidence to support this is poor; in addition, uncoated enzyme replacement therapy is not currently available in South Africa.

A possible mechanism of pain relief from pancreatic enzyme replacement therapies is a reduction in pancreatic stimulation by food-induced CCK. When exogenous pancreatic enzymes are taken with a meal, CCK-releasing factors are degraded and CCK release in response to a meal is reduced. However, clinical trials investigating this hypothesis have shown conflicting results. ${ }^{45,46}$ The majority of trials using enteric-coated preparations demonstrated no benefit, but this may reflect failure of the coated preparation to release the enzymes into the feedback-sensitive portion of the duodenum. In contrast, studies using non-enteric-coated tablets have demonstrated a reduction in pain compared with placebo. The effects of uncoated pancreatic enzymes are augmented by acid suppression therapy (either an $\mathrm{H}_{2}$ blocker or a proton pump inhibitor), which reduces the inactivation of the enzymes by gastric acid and increases the amount of protease to reach the duodenum. ${ }^{44,47}$ Enzyme therapy appears to be most effective in 'small-duct' or 'minimal change' CP. ${ }^{48}$ Octreotide, while also effective in reducing pancreatic secretion, is not currently recommended for treating chronic pain. ${ }^{44}$

In subjects with refractory severe pain, narcotic analgesics may be required, starting with the least potent agents and progressing to more potent formulations as necessary. Initially they should only be given on an 'as needed' basis. Ideally, ongoing regular opioid analgesia is reserved for those in whom endoscopic or surgical therapies are not appropriate and symptoms are intractable. Pethidine appears to be more addictive than other opiates and should be avoided wherever possible. Managing pain in CP is best done in conjunction with an experienced pain therapist who may wish to apply more specialised techniques such as intrapleural blocks.

Tricyclic antidepressants, selective serotonin re-uptake inhibitors and combined serotonin and norepinephrine re-uptake inhibitors will alleviate co-existent depression and may ameliorate pain and potentiate the effects of opiates. These agents may alter visceral and central nerve sensitisation, which are proposed mechanisms of pain in $\mathrm{CP}^{48}$

Antioxidants may be beneficial in reducing pain. A recent randomised, placebo-controlled trial of antioxidant supplementation in CP evaluated 147 patients over 6 months. ${ }^{49}$ The antioxidant supplementation consisted of daily doses of selenium, ascorbic acid, $\beta$-carotene, $\alpha$-tocopherol and methionine. Overall, antioxidant supplementation led to significantly less painful days per month, a reduced need for oral analgesics and fewer hospitalisations. The beneficial effect of these antioxidants on pain relief was already significant at 3 months. Whether these data are sufficient to recommend this intervention remains unclear.

\section{Recommendations}

- Chronic pain should be investigated to exclude pathologies which may be amenable to endoscopic or surgical therapy.

- Medical treatment of pain should employ a sequential (stepup) approach, commencing with simple, non-narcotic episodic analgesia (paracetomol or non-steroidal anti-inflammatory drugs), together with a low-fat diet.

- If simple analgesia is insufficient for pain control, a 6-week trial of high-dose pancreatic enzymes (in tablet, uncoated form) may be appropriate, if this is available. Acid suppression therapy should be given as an adjunct.

- In subjects with refractory severe pain, narcotic analgesics may be required, starting with the least potent agents and progressing to more potent formulations as necessary.

- Tricyclic antidepressants, selective serotonin re-uptake inhibitors and combined serotonin and norepinephrine re-uptake inhibitors, will alleviate co-existent depression and may ameliorate pain and potentiate the effects of opiates.

- Managing pain in $\mathrm{CP}$ is best done in conjunction with an experienced pain therapist.

\subsubsection{Treatment of pancreatic exocrine insufficiency}

Clinically significant malabsorption does not occur until more than $90 \%$ of pancreatic function is lost. ${ }^{44}$ Steatorrhoea usually occurs before protein deficiency. ${ }^{44}$ Enteric-coated preparations are superior to uncoated therapy for the treatment of steatorrhoea, as lipase is protected from inactivation by gastric acid. ${ }^{50}$ Clinical indications for initiating enzyme supplementation are frank steatorrhoea, weight loss or diarrhoea.

However, it has been shown that the sensitivity of clinical steatorrhea as a predictor of exocrine dysfunction is only $38 \%$, suggesting that exocrine insufficiency will go undetected and untreated in many patients. ${ }^{27}$ As such, asymptomatic patients with $\mathrm{CP}$ may benefit from routine screening for sub-clinical exocrine insufficiency, and receive pancreatic enzyme replacement if identified. This approach is recommended by some experts in the field, but is not validated. A suitable option for screening is the stool acid steatocrit determined on spot samples which is a reliable, easy and inexpensive test which, when compared with 72-hr stool quantitative faecal fat, displayed a sensitivity of $100 \%$ and a specificity of $95 \%{ }^{51}$ An alternative method 
of screening is the faecal elastase test, which is easy to perform, noninvasive and convenient. Unfortunately, these screening tests perform poorly in cases of mild to moderate pancreatic insufficiency.

Different formulations vary in lipase, protease, and amylase content. The aim is to provide at least $25-40000$ units of lipase per meal and $10-25000$ units of lipase with snacks. Because the cost is variable, one should consider the unit price of the enzyme supplement based on lipase content. The response to treatment is usually measured clinically by weight gain and improvement in symptoms, and the appropriate dose of enzyme replacement therapy needs to be titrated to maximise response. Despite an adequate clinical response, malabsorption may persist in some patients and higher doses (up to 60000 units of lipase per meal) may be necessary. ${ }^{52}$ Because of the possible risk of fibrosing colonopathy with very high doses of enzyme replacement, a ceiling of $75000 \mathrm{IU}$ of lipase per meal has been recommended by some..$^{50}$ It is essential that patients are counselled on the timing of enzyme ingestion in relationship to meals (enzymes should be ingested during a meal and not beforehand). Patients who remain symptomatic despite compliance with maximal enteric-coated enzyme replacement would benefit from the addition of acid-suppressing medication..$^{50}$ Other causes of diarrhoea should also be considered, in particular bacterial overgrowth, which is common in CP. ${ }^{53}$

\section{Recommendations}

- Pancreatic enzyme replacement therapy is recommended in patients with clinical features of exocrine insufficiency.

- Enteric-coated preparations are superior to uncoated therapy for the treatment of malabsorption.

- The preferred dose is a minimum of 25 - 40000 units of lipase per meal and 10 - 25000 units of lipase with snacks.

- The response to treatment is measured clinically by weight gain and improvement in symptoms.

- The appropriate dose of enzyme replacement therapy needs to be titrated to maximise response.

- Patients who remain symptomatic despite compliance with maximal enteric-coated enzyme replacement would benefit from the addition of acid-suppressing medication.

\subsubsection{Detection and treatment of endocrine insufficiency}

Up to $70 \%$ of patients with CP will eventually develop impaired glucose tolerance. The probability of endocrine insufficiency increases progressively within 10 years of disease onset. ${ }^{44}$ The diagnosis of endocrine insufficiency must be pursued early and aggressively by checking regular haemoglobin A1c (HBA1C) levels, fasting blood glucose or performing oral glucose tolerance testing. The optimal form of screening is debatable. Recently, an international expert committee with members appointed by the American Diabetes Association, the European Association for the Study of Diabetes, and the International Diabetes Federation recommended the use of HBA1C (at a level 26.5) rather than glucose for the diagnosis of diabetes. ${ }^{54}$ This is a significant departure from previous guidelines. Advantages of HBA1C are that it can be done without fasting and also shows much lower variation within individuals, compared with blood glucose.

Most pancreatic diabetics whose glycaemic control is refractory to dietary manipulation will eventually require insulin. Oral hypoglycaemic agents have little role to play in advanced disease. ${ }^{55}$ Pancreatic diabetics are at higher risk of experiencing severe hypoglycaemia than other forms of diabetes as a consequence of impaired glucagon secretion, malnutrition and concomitant hepatic dysfunction owing to alcohol abuse. Hence, patients with one or more episodes of severe hypoglycaemia may benefit from relaxation of glycaemic targets.

Long-term complications of pancreatic diabetes depend largely on the duration of the diabetes. Life expectancy is reduced, mainly due to persistent alcohol and nicotine abuse (cardiovascular disease, malignant tumours). Treatment of pancreatic diabetes should aim at optimising glucose control to prevent complications, while avoiding hypoglycaemia.

\section{Recommendations}

- The diagnosis of endocrine insufficiency must be pursued early and aggressively by checking regular HBA1C levels, fasting blood glucose or performing oral glucose tolerance testing.

- Treatment of pancreatic diabetes should aim at optimising glucose control to prevent complications, while avoiding hypoglycaemia.

\subsubsection{Nutrition}

Protein-calorie malnutrition is common in patients with CP and is often multifactorial, owing to abdominal pain, malabsorption, diabetes, altered gut motility and co-existent alcoholism. ${ }^{56}$ There is no specific 'CP diet'. In general, small meals and a diet low in fat and high in protein and carbohydrates are recommended, especially in patients with steatorrhoea. The degree of fat restriction depends upon the severity of fat malabsorption. Generally, an intake $<40-60 \mathrm{~g}$ per day is tolerated. Specific recommendations include a daily diet of 2 $500-3000$ calories, protein intake of $1.0-1.5 \mathrm{~g} / \mathrm{kg} /$ day and $<30-40 \%$ of total calories consumed as fat per day. ${ }^{56}$

Medium chain triglycerides are directly absorbed by the small intestine without requiring lipase. They can be used to supplement lipids and caloric intake in patients with severe fat malabsorption, although their use is hindered by unpalatability.

Malabsorption of the fat-soluble vitamins (A, D, E and K) may also occur, although clinically symptomatic vitamin deficiency is rare. Vitamin $B_{12}$ deficiency can also develop. Vitamin $B_{12}$ is absorbed in the terminal ileum and complexed to intrinsic factor. When vitamin $\mathrm{B}_{12}$ enters the stomach, it binds haptocorrin (or R-protein). The haptocorrin is degraded in the small intestine by pancreatic enzymes, thus releasing $B_{12}$ which then binds to intrinsic factor. In patients with pancreatic insufficiency, vitamin $B_{12}$ can remain bound to haptocorrin and is not available for absorption by the terminal ileum. Patients with ongoing alcohol abuse are also at risk of thiamine (vitamin $B_{1}$ ), riboflavin (vitamin $\mathrm{B}_{2}$ ) and pyridoxine (vitamin $\mathrm{B}_{6}$ ) deficiencies. Vitamins should be replaced if serum levels indicate a deficiency.

Osteopaenia is a recognised complication of $\mathrm{CP}$; a one-off assessment of bone mineral density (DEXA) should be considered. ${ }^{57}$

\section{Recommendations}

- There is no specific diet that patients should be advised to follow.

- Small meals and a diet low in fat and high in protein and carbohydrates are advisable. The degree of fat restriction depends upon the severity of fat malabsorption and how it responds to enzyme supplementation.

- Medium-chain triglycerides can be used to supplement lipid and caloric intake in patients with severe fat malabsorption refractory to enzyme replacement.

- Patients are at risk of fat-soluble vitamin (A, D, E and K) and B12 deficiency.

- Osteopaenia is a recognised complication of $\mathrm{CP}$, and a oneoff assessment of bone mineral density (DEXA) should be considered. 


\subsubsection{Screening for pancreatic adenocarcinoma}

It is currently recommended that patients with hereditary pancreatitis enter a screening programme, beginning at the age of 40 years. ${ }^{58}$ Screening should be done annually. Imaging options include EUS, multiphasic helical CT or MRI/MRCP. The use of ERCP is controversial, given the invasive nature of this investigation. The imaging modality of choice will vary depending on the capabilities and preferences of the institution or hospital. The value of screening other forms of $\mathrm{CP}$ is unclear and not currently recommended. However, as CP (regardless of aetiology) is a known risk factor for cancer occurrence, any significant change in symptoms should prompt further investigation.

\section{Recommendation}

- Patients with hereditary pancreatitis should enter a screening programme for adenocarcinoma, beginning at the age of 40 years.

- Routine screening of other forms of $\mathrm{CP}$ for adenocarcinoma is not currently recommended, but any significant change in symptoms should prompt further investigation.

\subsubsection{Autoimmune chronic pancreatitis}

Special mention must be made of auto-immune CP, as alternative therapies - notably corticosteroids - may be effective treatment. It was felt that this topic was a distinct entity and beyond the scope of this guideline.

\section{Interventional procedures}

While the majority of patients with $\mathrm{CP}$ can be managed adequately with medical therapies, surgical and non-operative interventional procedures can play an important role in selected cases with intractable pain, in uncomplicated disease and in the management of complications. The decision to intervene should be based on a multi-disciplinary approach, preferably in a centre experienced in the medical and surgical management of pancreatic disease.

\subsection{Management of pain in uncomplicated disease}

The decision to intervene should be carefully weighed up against the risk of complications and long-term sequelae of the procedure. It is important to stress that the indications for seemingly less invasive non-operative interventional procedures should not be different to that of surgery. Other causes of foregut pain should be excluded by appropriate investigations. Intervention should be considered when a stepwise approach to pain control (see par. 1.4.2) has failed to achieve adequate pain control, and when there is concern about opioid dependency, impaired quality of life and inability to work.

The timing of surgery is particularly problematic. It is often difficult to find a balance between early operations, which may compromise pancreatic function, and the risk of opioid addiction when conservative treatment is prolonged. ${ }^{59}$ Interventions should be considered if there is an escalated need and/or continuous usage of opioids. Patients must be carefully counselled on the risks of the procedure and informed that their pain may not be relieved satisfactorily. It should also be emphasised that interventions are unlikely to improve or prevent exocrine and endocrine insufficiency.

\section{Principles of interventional procedures}

It is generally accepted that the pathogenesis of pain in uncomplicated $\mathrm{CP}$ is multi-factorial ${ }^{59}$ and that it is difficult to determine which of these, or combinations thereof, are pertinent in an individual patient. Nonetheless, interventional procedures are either directed at addressing the morphological changes of the pancreatic duct system (strictures and stones), and inflammatory changes of the parenchyma, or by neurolysis of its nerve supply.

\subsubsection{Endoscopic treatment}

Endoscopic treatment addressing strictures and stones with or without extracorporeal shock wave lithotripsy (ESWL) has been utilised with increasing frequency in specialised gastrointestinal units. Success rates varying from $50-85 \%$ at $15-25$ months have been reported. ${ }^{60}$ ESWL can produce equally good results when compared with a combination of ESWL and endoscopic treatment, with a significant reduction in cost as shown in one trial. ${ }^{61}$ In two RCTs, ${ }^{62,63}$ surgery produced superior results to endoscopic therapy, but the interpretation of the results was hampered by the small percentage of patients eligible for the study and, in one report, ${ }^{62}$ surgery was only superior to endoscopic therapy in the intention-totreat group, and not in those patients who were randomised.

Endoscopic treatment requires a high level of endoscopic expertise and is labour-intensive. Furthermore, it carries risks such as bleeding, perforation and sepsis. There is also concern about ductal and parenchymal injury with long-term stenting.

\section{Recommendation}

While endoscopic treatment provides inferior results to surgery for long-term pain control in uncomplicated CP, it would seem reasonable to offer this less invasive, but technically-demanding treatment option, in the small sub-group of patients with localised strictures and stones in the main pancreatic duct. Long-term stenting should be avoided, and the role of ESWL outside specialised centres remains uncertain.

\subsubsection{Neurolysis}

The results of celiac plexus block using a variety of neurolytic agents (e.g. ethanol or phenol) have been disappointing. ${ }^{64}$ The procedure also carries risks related to the necrosing effects of the agents. EUSguided neurolysis is purported to be safer; a meta-analysis on pain control showed a $60 \%$ response rate ${ }^{65}$ However, there is no indication that long-term results are better than those of other methods. ${ }^{66}$

With the advent of minimal access surgery, there has been renewed interest in thoracoscopic splanchnicectomy. There is a belief that this form of neurolysis, when performed bilaterally, provides a more complete interruption of the sympathetic nerves that transmit the afferent paths of pancreatic pain. But, as in the case of coeliac plexus blocks, long-term results are disappointing, particularly in young patients ( $<45$ years) and in those who had previous pancreatic surgery. ${ }^{67}$ Open surgical denervation procedures are no longer performed.

\section{Recommendation}

Neurolysis has no place in the long-term control of pain in CP.

\subsubsection{Surgery}

Surgery in one form or another provides the best chance for long-term pain relief in uncomplicated disease and can also address associated complications such as bile duct and or duodenal obstruction. Surgery is also indicated in cases where malignancy is suspected or cannot be excluded. These are complex procedures and should only be undertaken by surgeons with specialised training in pancreatic surgery working in a multi-disciplinary environment. In addition, all other treatment options should have been exhausted or be inappropriate. Surgery should only be undertaken once patients have been carefully evaluated for co-morbid diseases and when the morphological changes of the pancreas have been clearly delineated by modern cross-sectional imaging. It is particularly important to 
determine the presence of associated portal hypertension which may preclude surgical intervention.

Numerous surgical procedures have been devised since Gould ${ }^{68}$ successfully removed calculi from Wirsung's duct in 1898. Table IV lists the most commonly performed operations performed today and indicates their selection based to a large extent on parenchymal and pancreatic ductal morphological changes of the pancreas. Surgery should be carried out with minimal morbidity and mortality and with maximum preservation of pancreatic function. To this end, there has been a paradigm shift away from the standard resection procedures, such as the classic Whipple's (CW) and pylorus preserving pancreaticoduodenectomy (PPPD), to organ-preserving resection operations such as the Frey and Beger operations and hybrid modifications. A detailed review of the results of the various surgical procedures is beyond the scope of these guidelines; but, based on reviews on the subject and RCTs, ${ }^{69-72}$ the following conclusions can be drawn:

Table IV. The most common surgical options for CP

\begin{tabular}{ll}
\hline Procedures & Indications \\
Resection: & \\
- pancreaticoduodenectomy & - suspicion of malignancy \\
- distal pancreatectomy & - disease confined to the body \\
& and tail of the pancreas \\
Duodenal-preserving & - inflammatory mass of the \\
resection of the head of the & head of the pancreas, with or \\
pancreas & $\begin{array}{l}\text { without a dilated pancreatic } \\
\text { duct }\end{array}$ \\
Pancreatico-jejunostomy & - dilated pancreatic duct \\
& without inflammatory mass in \\
& the head of the pancreas.
\end{tabular}

- Classic Whipple's operation (CW) is associated with a higher morbidity and mortality, greater weight loss and poorer quality of life (QOL) compared with the organ-preserving operations. The operation is now reserved for patients with a suspected malignancy.

- Distal pancreatectomy is indicated in carefully selected patients where the disease is confined to the distal pancreas with isolated ductal obstruction, with or without a pseudocyst. ${ }^{73}$ Extended distal pancreatectomy $(>80 \%)$ for diffuse disease is associated with poor long-term outcome in terms of pain control, and is associated with a high incidence of diabetes. ${ }^{74}$ Likewise, total pancreatectomy should only be considered in rare cases after previous failed operations. Islet Island cell transplantation, to address the problem of diabetic control in this setting, has been performed by a few centres with variable results. ${ }^{75}$

- Pylorus preserving pancreatico-duodenectomy (PPPD). Studies comparing PPPD with the Beger operation have produced conflicting results in terms of morbidity, pain relief and functional outcome, but on balance favour the latter. However, the earlier functional advantages of the Beger operation were no longer evident in one long-term follow-up study. ${ }^{76}$ The results were more clearly in favour of the Frey procedure when this was compared with PPPD in two RCTs. ${ }^{77,78}$ PPPD is mainly reserved for cases with suspicion of malignancy, or selected patients with an inflammatory mass in the head of the pancreas associated with biliary and duodenal obstruction.

- Organ-preserving operations. The most commonly performed preserving operations are the Frey and Beger procedures and their hybrid modifications. In one RCT comparing these two operations, ${ }^{79}$ Strate et al. showed no difference in their longterm outcome. The Frey operation is currently the most widelyperformed, duodenal-preserving resection operation for patients with an inflammatory mass in the head of the pancreas associated with a dilated pancreatic duct system, while the Beger procedure is reserved for non-dilated ducts. Alternatively, Izbicki et al. ${ }^{80}$ introduced a modified $\mathrm{V}$-shaped excision of the ventral pancreas with a pancreatico-jejunostomy for ducts $<3 \mathrm{~mm}$ in size, with seemingly equally good results.

- Standard pancreatico-jejunostomy (Partington and Rochelle). This operation has a limited role and may be indicated in patients with a dilated pancreatic duct without an inflammatory mass in the head of the pancreas. It may also be indicated when there is an associated pseudocyst. ${ }^{81}$

The results of the above operations ${ }^{69}$ are similar, but the trend is in favour of organ-preserving operations. In expert hands, operative morbidity is about $30 \%$ and mortality $<1 \%$. Long-term ( $5-7$ years) pain relief varies from $80-90 \%$, and new-onset diabetes occurs in one- third, and steatorrhoea in two-thirds, of patients. The functional abnormalities identified in long-term follow-up are a reflection of the natural history of the disease, rather than the outcome from an individual operation. ${ }^{76}$ QOL is improved in most patients, with 36 $75 \%$ returning to work. Some reports suggest that long-term QOL after surgery remains poor due to the lifestyle and co-morbidities, particularly after resection operations. ${ }^{82}$

Life expectancy is shortened in patients with CP, and late mortality (10 years) after surgery occurs in about a third of patients. Pancreatic cancer is the cause of death in up to $10 \%$ of cases. Deaths due to smoking-related diseases are also common, as are deaths due to the complications of diabetes in the indigent patient.

\section{Recommendation}

In carefully selected cases, surgery has an important role to play in the management of intractable pain in CP. The choice of surgery is governed to a large extent by the size of the pancreatic duct and the presence or absence of an inflammatory mass in the head of the pancreas. The principles of surgery are to minimise morbidity and mortality and to preserve exocrine and endocrine pancreatic function. The classic Whipple's operation has now been superseded by organpreserving resection. Surgery should be performed in specialised centres, with the emphasis on a multi-disciplinary approach.

\subsection{Complications in CP}

\subsubsection{Pseudocysts (pancreatic fluid collections) and} ascites

Pancreatic fluid collections (or pseudocysts, to which they are more commonly referred) occur in $30-40 \%$ of patients with CP. The pathogenesis is thought to be due to two main processes as described by D'Egidio and Schein. ${ }^{83}$ 'Retention cysts' may be the result of ductal obstruction, while pancreatic necrosis with ductal disruption and leak of pancreatic fluid may develop during an episode of acute on chronic pancreatitis. A clear distinction should be made between postnecrotic fluid collections following acute necrotising pancreatitis, and those occurring in patients with established CP. The former are usually immature collections containing necrotic material, whereas the latter consists mainly of pancreatic fluid, rich in amylase. The pseudocysts in CP are often intra-pancreatic (mostly located in the head) or confined to the lesser sac. ${ }^{84}$ Pancreatic ascites occurs when there is rupture of a pseudocyst or duct into the peritoneal cavity.

Pseudocysts in CP present with pain or obstruction to neighbouring structures, causing mostly biliary or gastric outlet obstruction. They can also present with erosion into blood vessels and the formation of 
a pseudo-aneurysm which can present as GIT bleeding when there is communication with the pancreatic duct (haemosuccus pancreas) or bleeding into the pseudocyst. Pseudocysts can also become infected, but this occurs less often than in cases with acute post-necrotic fluid collections.

CT scanning remains the imaging modality of choice, but MRI and MRCP are gaining in popularity. The role of ERCP as a diagnostic modality is waning as the information required can be determined from MRCP. It is of paramount importance to differentiate pseudocysts from cystic tumours of the pancreas which are now more readily diagnosed with modern cross-sectional imaging. A review on how to differentiate pseudocysts from cystic neoplasm is beyond the scope of these guidelines, but is based on clinical and morphological features and cyst fluid analysis. A cystic neoplasm should be strongly suspected in patients without a history of alcohol abuse, and/or previously confirmed attacks of pancreatitis - especially in middleaged women.

The indications for the treatment of pseudocysts are the presence of symptoms or complications. It is recognised that larger pseudocysts $(>6 \mathrm{~cm})$ will be symptomatic more often and, as such, will require treatment more often, but size alone is not necessarily an indication for treatment. There is very little level 1 evidence to support any particular treatment option in the management of pseudocysts. However, there is growing consensus to support endoscopic drainage with or without EUS as the first line of treatment. The procedure has a high success rate, is a lesser procedure than surgery and has a good safety record. ${ }^{85}$ EUS-guided drainage has broadened the scope of endoscopic drainage ${ }^{86-88}$ and is purported to increase the safety of the procedure - particularly in the presence of portal hypertension. The most common endoscopic drainage approach is transduodenal or transgastric, but the trans-papillary approach is also used and is an alternative method in cases unsuitable for the former.

Simple aspiration or the placement of external drainage catheters is usually inappropriate for pseudocysts in $\mathrm{CP}$ owing to a high failure rate and potential risk of a persistent external fistula, as most of these collections communicate with the pancreatic duct. In selected cases, it may be useful as a temporary measure in patients with very large and symptomatic lesser sac pseudocyst.

In selected patients, percutaneous transgastric drainage placement, combined sometimes with endoscopic therapy, may be a useful approach to managing the pseudocyst.

Surgery is indicated in cases unsuitable for non-operative drainage, failures after endoscopic treatment and in the presence of life-threatening complications. Surgery may also be the preferred treatment in cases with other associated complications such as biliary and duodenal obstruction, and when there is gross pancreatic duct dilatation, with or without an inflammatory mass in the head of the pancreas. ${ }^{59}$

In the main, the choice of surgical procedures will be dictated by the location of the pseudocyst and its proximity to the bowel wall. Cyst drainage procedures were commonly used in the past. In this procedure, lesser sac collections are drained via the posterior wall of the stomach (cyst-gastrostomy) and those close to the duodenum by way of a cyst-duodenostomy or Roux-en-Y cyst-jejunostomy. The disadvantage of these procedures is that when there are associated underlying ductal and parenchymal abnormalities, patients may continue to experience ongoing pain. As such, organ-preserving procedures (i.e. Frey procedure) may be the preferred treatment. Distal pancreatectomy is indicated in cases with segmental disease in the body/tail of the pancreas and an associated pseudocyst, 73 and in cases with a suspicious cystic tumour.

\subsubsection{Complications associated with pseudocysts Infection}

While percutaneous drainage is generally recommended for infected pseudocyst, there is a growing trend to treat endoscopically those occurring in CP. Surgery is indicated if non-operative treatment fails, or is not available.

\section{Pancreatic ascites and pleural effusion}

No clear guidelines can be derived from current publications on this rare complication. Conventional treatment strategies include bed rest with nutritional support by parenteral/enteral feeding, paracentesis, and the use of somatostatin analogues. However, there is no objective evidence that any of these treatment modalities, including somatostatin analogues, have a major effect on the natural history, bearing in mind that the ascites or pleural effusion will resolve spontaneously in a substantial percentage of cases. Prolonged conservative treatment with parenteral nutrition should be avoided as this increases the risk of sepsis. ${ }^{89}$ Endoscopic intervention (papillotomy/stenting) with the aim of sealing off the leak and overcoming a distal obstruction should be considered early after initial supportive intravenous nutritional therapy. The success rate varies in published series, but may be high in skilled hands. ${ }^{90}$ Surgery to address the leak and underlying pathology is now reserved for failures of endoscopic treatment.

\section{Haemorrhage}

Haemorrhage associated with CP may be due to analgesic-induced peptic ulceration, false aneurysms related to pseudocysts, or gastric varices secondary to segmental portal hypertension. Bleeding from a false aneurysm can in the majority of cases be treated with selective angiographic embolisation. ${ }^{91}$ When surgery is required, the procedure should be aimed at vascular control and not definitive treatment of the $\mathrm{CP}$, unless the bleeding site is in the tail of the pancreas, in which case a distal pancreatectomy is indicated. Most patients with segmental portal hypertension will not bleed from gastric varices. A splenectomy should therefore only be performed when there is proven bleeding from gastric varices.

\section{Recommendations}

- Only symptomatic pseudocyst should be treated, and size alone is not an indication to intervene.

- The lack of distinction between acute post-necrotising pseudocysts from those occurring in $\mathrm{CP}$ in published series has made it difficult to recommend a particular interventional procedure.

- In suitable cases, endoscopic treatment is the preferred treatment, the scope of which has increased when performed under EUS guidance.

- Surgery is reserved for cases unsuitable for endoscopic drainage and failures with recurrence of pain, with or without recurrence of the pseudocyst.

- In selected cases, the underlying pancreatic pathology should be addressed with appropriate combined resection and drainage procedures.

- Haemorrhage from false aneurysms related to pseudocyst is best controlled by selective angiographic embolisation.

- Endoscopic intervention is indicated in patients with persistent pancreatic ascites/pleural effusion.

\subsubsection{Duodenal obstruction}

The management of patients with persistent duodenal obstruction will depend on the underlying cause. Drainage of a large pseudocyst by whichever means would resolve the problem but, when it is 
due to residual fibrosis, some form of surgical intervention would be required. In some instances, mobilisation of the duodenum by way of a Kocher's manoeuvre would suffice. It is very difficult to find consensus on the best surgical procedure. There may be situations were a duodeno-duodenostomy or a duodeno-jejunostomy or a gastro-jejunostomy may be appropriate. When associated with a biliary obstruction and an inflammatory mass in the head of the pancreas, consideration should be given to performing a pyloruspreserving pancreaticoduodenectomy.

\subsubsection{Bile duct obstruction}

Obstruction of the biliary tree is common during the advanced stages of CP, particularly when associated with calcification and an inflammatory mass in the head of the pancreas. Obstruction can be caused by oedema, an intrapancreatic pseudocyst or fibrosis. The natural history of the obstruction will vary according to the underlying pathology. The clinical presentation varies from an incidental discovery to overt jaundice, with or without associated cholangitis. Jaundice that occurs during acute exacerbations is often transient and may resolve completely without requiring intervention. The risk of developing secondary biliary cirrhosis is low, particularly in non- jaundiced patients who present with raised alkaline phosphatase (ALP) or a dilated biliary system on imaging. ${ }^{92}$ Persistent jaundice occurs when there is progressive fibrosis, with or without calcification.

\section{Diagnosis}

\section{Liver function tests}

A disproportionately-raised ALP and gamma GT is typically seen in patients with low-grade obstruction. In jaundiced patients, liver function tests frequently improve, which is useful to distinguish benign from malignant obstruction. CA 19-9 may be elevated in CP with biliary obstruction, although levels seldom exceed $100-120 \mathrm{U} /$ $\mathrm{ml}^{93}$

\section{Imaging}

While ultrasound is usually the first imaging modality to identify biliary obstruction, CT scan is required to define the nature and extent of the disease, and to help differentiate $\mathrm{CP}$ from a pancreatic cancer. MRCP is the preferred imaging to delineate the bile duct stricture and pancreatic duct anatomy. Although a smooth tapering of the distal bile duct is suggestive of $\mathrm{CP}$, this finding is not reliable enough on its own to distinguish it from a carcinoma. ERCP is reserved in the main when intervention is required. Endoscopic brush cytology has a very good specificity but poor sensitivity in the diagnosis of malignancy, yet is a valuable adjunct to diagnosis and should be considered in patients undergoing ERP. ${ }^{94}$

\section{Management}

Management is largely dictated by the clinical presentation and morphological changes of the pancreas. Clinical factors to consider include the presence and severity of associated pain, the occurrence of jaundice and duration thereof, concern about malignancy and co-morbid diseases. Surgical strategy will depend on the presence of an inflammatory mass in the head of the pancreas and the degree of bile duct and pancreatic duct dilatation. ${ }^{92}$

\section{Recommendations}

- Patients with asymptomatic bile duct strictures, including those with an isolated raised ALP, should be treated conservatively with regular follow-ups.
- Endoscopic interventions and stenting should be discouraged, as this may cause secondary infection, particularly when the stents occlude. There is no need to perform regular liver biopsies to detect the development of secondary liver cirrhosis in this group of patients.

- Patients who present with jaundice should initially be treated conservatively, unless associated with cholangitis, when a temporary stent should be placed. If jaundice resolves, no further intervention is required, but the patient will require follow-ups.

- A surgical bypass, preferably a hepatico-jejunostomy, is acceptable in the relatively uncommon scenario when jaundice persists in the absence of any other sequelae of the CP.

- A Frey procedure with a hepatico-jejunostomy is the preferred operation when there is an inflammatory mass in the head of the pancreas associated with a dilated pancreatic duct. In the absence of a dilated duct, a pylorus-preserving pancreaticoduodenectomy could be performed, as well as in those patients where a malignancy is suspected.

- The current recommendation for stenting is in patients who present with cholangitis and those unfit for surgery owing to severe co-morbid diseases. The indications for stenting may expand with the development of removable expandable stents in those patients where jaundice is the predominant clinical presentation.

\section{Summary and conclusion}

Alcohol is by far the most common causative agent in the development of $\mathrm{CP}$, and the prognosis is therefore to a large extent dependent on abstinence, together with cessation of smoking. While the natural history is usually characterised by marked progression of the disease associated with increasing severity in pain with the associated risk of narcotic dependency, there is a subgroup of patients where the disease runs a more benign course. Endocrine and exocrine insufficiency is a late manifestation. In patients with progressive disease, life expectancy is shortened by associated pancreatic complications, malnutrition and diseases related to smoking.

The mainstay of treatment is abstinence from alcohol and smoking, with careful pain control that requires close monitoring to reduce the risk of opioid dependency. During the late stages of the disease, medical treatment emphasis may shift to include diabetic control, exocrine pancreatic replacement therapy and nutritional support.

The role of endoscopic therapy for pain control in uncomplicated disease is limited, while organ-preserving operations in carefully selected patients with intractable pain may provide long-term relief. However, in selected cases, endoscopic therapy has become the treatment of choice for complicated disease, especially pseudocysts.

$\mathrm{CP}$ is a complex disease which requires a multi-disciplinary approach by specialists in this field, particularly when interventional procedures are to be considered for intractable pain and other complications.

\section{Guideline sponsorship}

The guideline process was supported and funded by Solvay Pharma (now Abbott Products), who covered the full costs as a grant to the HPBASA and SAGES,

\section{Acknowledgements}

The authors thank Meredith Chambers, Mia Nell and Helena Essel for their dedicated and tireless assistance in compiling this guideline. 


\section{GUIDELINES}

\begin{tabular}{|c|c|c|c|c|c|}
\hline \multicolumn{6}{|c|}{ Rosemont criteria: Consensus-based parenchymal features of $\mathbf{C P}^{21}$} \\
\hline A & Definition & Major criteria & Minor criteria & Rank & $\begin{array}{l}\text { Histological } \\
\text { correlation }\end{array}$ \\
\hline $\begin{array}{l}\text { Hyperechoic foci } \\
\text { with shadowing }\end{array}$ & $\begin{array}{l}\text { Echogenic structures } \\
\geq 2 \mathrm{~mm} \text { in length and } \\
\text { width that shadow }\end{array}$ & Major A & & 1 & $\begin{array}{l}\text { Parenchymal-based } \\
\text { calcifications }\end{array}$ \\
\hline Lobularity & $\begin{array}{l}\text { Well- circumscribed, } \\
\geq 5 \mathrm{~mm} \text { structures, } \\
\text { with enhancing rim } \\
\text { and relatively echo- } \\
\text { poor centre }\end{array}$ & & & 2 & Unknown \\
\hline $\begin{array}{l}\text { A. With } \\
\text { honeycombing }\end{array}$ & $\begin{array}{l}\text { Contiguous } \geq 3 \\
\text { lobules }\end{array}$ & Major B & & & \\
\hline $\begin{array}{l}\text { B. Without } \\
\text { honeycombing }\end{array}$ & $\begin{array}{l}\text { Non-contiguous } \\
\text { lobules }\end{array}$ & & Yes & & \\
\hline $\begin{array}{l}\text { Hyperechoic foci } \\
\text { without shadowing }\end{array}$ & $\begin{array}{l}\text { Echogenic structures } \\
\text { foci } \geq 2 \mathrm{~mm} \text { in both } \\
\text { length and width } \\
\text { with no shadowing }\end{array}$ & & Yes & 3 & Unknown \\
\hline Cysts & $\begin{array}{l}\text { Anechoic, rounded/ } \\
\text { elliptical structures, } \\
\text { with or without } \\
\text { septations }\end{array}$ & & Yes & 4 & Pseudocyst \\
\hline Stranding & $\begin{array}{l}\text { Hyperechoic lines } \\
\geq 3 \mathrm{~mm} \text { in length in } \\
\text { at least } 2 \text { different } \\
\text { directions with } \\
\text { respect to the image } \\
\text { plane }\end{array}$ & & Yes & 5 & Unknown \\
\hline \multicolumn{6}{|c|}{ Rosemont criteria: Consensus-based ductal features of $\mathrm{CP}^{21}$} \\
\hline Feature & Definition & Major criteria & Minor criteria & Rank & $\begin{array}{l}\text { Histological } \\
\text { correlation }\end{array}$ \\
\hline MPD calculi & $\begin{array}{l}\text { Echogenic } \\
\text { structure(s) within } \\
\text { MPD with acoustic } \\
\text { shadowing }\end{array}$ & Major A & & 1 & Stones \\
\hline $\begin{array}{l}\text { Irregular MPD } \\
\text { contour }\end{array}$ & $\begin{array}{l}\text { Uneven or irregular } \\
\text { outline and ectatic } \\
\text { course }\end{array}$ & & Yes & 2 & Unknown \\
\hline Dilated side branches & $\begin{array}{l}\geq 3 \text { tubular anechoic } \\
\text { structures each } \\
\text { measuring } \geq 1 \mathrm{~mm} \text { in } \\
\text { width, budding from } \\
\text { the MPD }\end{array}$ & & Yes & 3 & Side-branch ectasia \\
\hline MPD dilation & $\begin{array}{l}\geq 3.5 \mathrm{~mm} \text { body or } \\
>1.5 \mathrm{~mm} \text { tail }\end{array}$ & & Yes & 4 & MPD dilation \\
\hline $\begin{array}{l}\text { Hyperechoic MPD } \\
\text { margin }\end{array}$ & $\begin{array}{l}\text { Echogenic, distinct } \\
\text { structure }>50 \% \text { of } \\
\text { entire MPD in the } \\
\text { body and tail }\end{array}$ & & Yes & 5 & Ductal fibrosis \\
\hline
\end{tabular}




\section{Addendum B}

\section{EUS diagnosis of $\mathrm{CP}$ on the basis of consensus criteria} I. Consistent with $\mathrm{CP}$

A. 1 major A feature $(+) \geq 3$ minor features

B. 1 major A feature (+) major B feature

C. 2 major A features

\section{Suggestive of $\mathbf{C P}^{*}$}

A. 1 major A feature $(+)<3$ minor features

B. 1 major B feature $(+) \geq 3$ minor features

C. $\geq 5$ minor features (any)

\section{Indeterminate for $\mathrm{CP}^{\dagger}$}

\section{A. 3 - 4 minor features, no major features}

B. major B feature alone or with $<3$ minor features

\section{Normal}

$\leq 2$ minor features, ${ }^{\ddagger}$ no major features

EUS diagnosis of CP should be made in the appropriate clinical setting.

${ }^{\dagger}$ Diagnosis requires confirmation by additional imaging study (ERCP, CT, MRI or PFT).

Excludes cysts, dilated MPD, hyperechoic non-shadowing foci, dilated side branch.

\section{References}

Clain JE, Pearson RK. Diagnosis of chronic pancreatitis: is a gold standard necessary? Surg Clin North Am 1999;79:829-845.

Segal I. Pancreatitis in Soweto, South Africa. Digestion 1998;59(40):25-35

3. Chocquet M, Menke H, Ledoux S. Self-reported alcohol consumption among adolescents and the significance of early onset. A longitudinal approach. Soc Psychiatry Psychiatr Epidemiol 1989;24:102 112

4. Pandol SJ, Ratay M. Pathobiology of alcoholic pancreatitis. Pancreatology 2007;7:105-114.

Layer P, Hironori Y, Kalthoff L, et al. The different courses of early- and late-onset idiopathic and alcoholic chronic pancreatitis. Gastroenterology 1994;107:1481-1487.

6. Ammann RW, Muellhaupt B, Zurich Pancreatitis Study Group. The natural history of pain in alcoholic chronic pancreatitis. Gastroenterology 1999;116:1132-1140.

chronic pancreatitis. Gastroenterology 1999;116:1132-1140. milabsorption in severe pancreatic insufficiency. N Engl J Med 1973;288:813-815.

8. Toskes PP, Hansell J, Cerda J, Deren JJ. Vitamin B12 mal-absorption in chronic pancreatic insufficiency. N Engl J Med 1971;284:627-632

Malka D, Hammel P, Sauvanet A, et al. Risk factors for diabetes mellitus in chronic pancreatitis Gastroenterology 2000;119:1324-1332.

. Lowenfels $\mathrm{AB}$, Maisonneuve $\mathrm{P}$, Cavallini G, et al. Pancreatitis and the risk of pancreatic cancer International Pancreatitis Study Group. N Eng J Med 1993;328:1433-1437.

11. Buscail L, Escourrou J, Moreau J, et al. Endoscopic ultrasonography in chronic pancreatitis: comparative prospective study with conventional ultrasonography, computed tomography, and ERCP. Pancreas 1995;10:251-257.

12. Malfertheiner P, Buchler M, Stanescu A, Ditschuneit H. Exocrine pancreatic function in correlation to ductal and parenchymal morphology in chronic pancreatitis. Hepato-gastroenterology 1986;33:110114.

\section{North Am 1989:27:51-64.}

14. Sahai AV Zimmerman M, Aabakken L, et al. Prospective assessment of the ability of endoscopic ultrasound to diagnose, exclude, or establish the severity of chronic pancreatitis found by endoscopic retrograde cholangio-pancreatography. Gastrointest Endosc 1998;48:18-25.

15. Catalano MF, Lahoti S, Geenen JE, Hogan WJ. Prospective evaluation of endoscopic ultrasonography, endoscopic retrograde pancreatography, and secretin test in the diagnosis of chronic pancreatitis. Gastrointest Endosc 1998;48:11-17

16. Weirsema MJ, Hawes RH, Lehman G, Kochman ML, Sherman S, Kopecky KK. Prospective evaluatio of endoscopic ultrasonography and endoscopic retrograde cholangiopancreatography in patients with chronic abdominal pain of suspected pancreatic origin. Endoscopy 1993;25:555-564.

17. Kahl S, Glasbrenner B, Leodolter A, Pross M, Schulz HU, Malfertheiner P. EUS in the diagnosis of early chronic pancreatitis: a prospective follow-up study. Gastrointest Endosc 2002;55:507-51 .

18. Hollerbach S, Klamann A, Topalidis T, Schmeigel WH. Endoscopic ultrasonography (EUS) and fine needle aspiration (FNA) cytology for diagnosis of chronic pancreatitis. Endoscopy 2001;33:824-831

19. Hastier P, Buckley MJ, Francois E, et al. A prospective study of pancreatic diseases in patients with alcoholic cirrhosis: comparative diagnostic value of ERCP and EUS and long-term significance of isolated parenchymal abnormalities. Gastrointest Endosc 1999;49:705-709.

20. International Working Group for Minimum Standard Terminology for Gastrointestinal Endoscopy. Reproduction of minimum standard terminology in gastrointestinal endosonography. Dig Endosc 1998;10:158-188.

21. Catalano MF, Sahai A, Levy M, et al. EUS-based criteria for the diagnosis of chronic pancreatitis: the Rosemont classification. Gastrointest Endosc 2009;69:1262-1263.

22. Ueno E, Takada Y, Yoshida I, Toda J, Sugiura T, Toki F. Pancreatic diseases: Evaluation with MR cholangiopancreatography. Pancreas 1998;16:418-426.
23. Yamaguchi K, Chijiwa K, Shimizu S, Yokohata K, Morisaki T, Tanaka M. Comparison of endoscopic retrograde and magnetic resonance cholangiopancreatography in the surgical diagnosis of pancreatic disease. Am J Surg 1998;175:203-208.

24. Kinney TP, Punjabi G, Freeman M. Technology insight: Applications of MRI for the evaluation of benign disease of the pancreas. Nat Clin Pract Gastroenterol Hepatol 2007;4:148-159.

5. Sarner M Cotton PB. Classification of pancreatitis. Gut 1984:25:756-759.

26. Luk GD. Same questions, different answers. Gastroenterology 1979;76:891-892.

27. Dumasy V, Delhaye M, Cotton F, Deviere J. Fat malabsorption screening in chronic pancreatitis. Am J Gastroenterology 2004;99:1350-1354

28. Niederau C, Grendell JH. Diagnosis of chronic pancreatitis. Gastroenterology 1985;88:1973-1995.

29. Gullo L, Ventrucci M, Tomassetti P, Migliori M, Pezzilli R. Fecal elastase 1 determinations in chronic pancreatitis. Dig Dis Sci 1999;44:210-213.

30. Schneider A, Löhr JM, Singer MV. The M-ANNHEIM Classification of Chronic Pancreatitis: Introduction of a unifying classification system based on a review of previous classifications of the disease. J Gastroenterology 2007;42:101-119.

1. Reinert DF, Allen IP. The Alcohol Use Disorders Identification Test (AUDIT): A review of recent research. Alcohol Clin Exp Res 2002;2:272-279.

32. Patton R, Hilton C, Crawford MJ, Touquet R. The Paddington Alcohol Test: a short report. Alcohol 2004;39:266-268.

33. Talamini $G$ Bassi C. Falconi $M$, et al. Alcohol and smoking as risk factors in chronic pancreatitis and pancreatic cancer. Dig Dis Sci 1999;44:1301-1311.

34. Lin Y, Tamakoshi A, Hayakawa T, Ogawa M, Ohno T. Cigarette smoking as a risk factor for chronic pancreatitis: a case-control study in Japan. Research Committee on Intractable Pancreatic Diseases. ancreas 2000;21:109-114

35. Whitcomb DC, Gorry MC, Preston RA, et al. Hereditary pancreatitis is caused by a mutation in the cationic trypsinogen gene. Nat Genet 1996;14:141-145.

36. Sharer N, Schwarz M, Malone G, et al. Mutations of the cystic fibrosis gene in patients with chronic pancreatitis. N Engl J Med 1998;339:687-688.

37. Pfützer RH, Barmada MM, Brunskil APJ, et al. SPINK1/PSTI polymorphisms act as disease modifiers in familial and idiopathic chronic pancreatitis. Gastroenterology 2000;119:615-623.

38. Finkelberg DL, Sahani D, Deshpande V, Brugge WR. Auto-immune pancreatitis. New Engl J Med 2006;335:2670-2676.

39. Akari T, Ueda M, Ogawa $\mathrm{K}$, Tsuji T. Histological pancreatitis in end-stage renal disease. Int J Pancreatology 1992;12:263-269.

40. Mergener K, Baillie I. Chronic pancreatitis. Lancet 1997:340:1379-1385.

11. Gullo L, Barbara L, Labo G. Effect of cessation of alcohol use on the course of pancreatic dysfunction in alcoholic pancreatitis. Gastroenterology 1988;95:1063-1068.

2. Maisonneuve $\mathrm{P}$, Lowenfels $\mathrm{AB}$, Mullhaupt $\mathrm{B}$, et al. Cigarette smoking accelerates progression of alcoholic chronic pancreatitis. Gut 2005;54:510-514

3. Warshaw AL, Banks PA, Fernàndez-Del Castillo C. AGA technical review: treatment of pain in chronic pancreatitis. Gastroenterology 1998;115:765-776.

4. Ahmad SA, Wray C, Rilo HL, et al. Chronic pancreatitis: recent advances and ongoing challenges. Curr Probl Surg 2006;43:127-138

5. Winstead Ns, Wilcox CM Clinical trials of pancreatic enzyme replacement for painful chronic pancreatitis - A review. Pancreatology 2009;9:344-350

46. Brown A, Hughes M, Tenner S, et al. Does pancreatic enzyme supplementation reduce pain in patients with chronic pancreatitis: a meta-analysis. Am J Gastroenterol 1997;92:2032-2035.

Heijerman HG, Lamers CB, Bakker W. Omeprazole enhances the efficacy of pancreatin (pancrease) in cystic fibrosis. Ann Intern Med 1991;114:200.

48. Lieb J.G, Forsmark CE. Review article: pain and chronic pancreatitis. Aliment Pharmacol Ther 2009;29:706-719.

49. Bhardwaj P, Garg PK, Maulik SK, Saraya A, Tandon RK, Acharya SK. A randomized controlled trial of antioxidant supplementation for pain relief in patients with chronic pancreatitis. Gastroenterology 2009;136:149-159.

50. Krishnamurty DM, Rabiee A, Jagannath SB, et al. Delayed release pancrelipase for treatment of pancreatic exocrine insufficiency associated with chronic pancreatitis. Ther Clin Risk Management 2009;5:507-520.

1. Amann ST, Josephson SA, Toskes PP. Acid steatocrit: A simple, rapid gravimetric method to determine steatorrhea. Am J Gastroenterol 1997;92:2280-2284.

52. Dominguez-Munoz JE, Iglesias-Garcia J, Vilarino-Insua M, et al. 13C-mixed triglyceride breath test to assess oral enzyme substitution therapy in patients with chronic pancreatitis. Clin Gastroenterol Hepatol. 2007;5:484-488.

53. Trespi E, Ferrieri A. Intestinal bacterial overgrowth during chronic pancreatitis. Curr Med Res Opin 1999;15(1):47-52.

54. International Expert Committee. International Expert Committee report on the role of the Alc assay in the diagnosis of diabetes. Diabetes Care 2009;32:1327-1334.

55. Joffe BI, Jackson WPU, Bank S, et al. Effect of oral hypoglycaemic agents on glucose tolerance in pancreatic diabetes. Gut 1972;13:285-288.

56. Scolapio IS, Malhi-Chowla N, Ukleja A. Nutrition supplementation in patients with acute and chronic pancreatitis. Gastroenterol Clin North Am 1999;28:695-707.

57. Haaber AB, Rosenfalck AM, Hansen B, et al. Bone mineral metabolism, bone mineral density, and body composition in patients with chronic pancreatitis and pancreatic exocrine insufficiency. Int J Pancreatology 2000;27:21-27.

5. Ulrich CD. Pancreatic cancer in hereditary pancreatitis: Consensus guidelines for prevention, screening and treatment. Pancreatology 2001;1:416-422.

59. Bornman PC. Chronic Pancreatitis. In: Garden OJ, ed. A Companion to Specialist Surgical Practice Hepatobiliary and Pancreatic Surgery. 4th ed. New York: WB Saunders Co, 2009:259-283.

60. Kozarek RA, Traverso LW. Endoscopic treatment of chronic pancreatitis: an alternative to surgery? Dig Surg 1996; 13: 90-100.

61. Dumonceau J-M, Costamangna G, Tringali A, et al. Treatment of painful calcified chronic pancreatitis: extracorporeal shock wave lithotripsy versus endoscopic treatment: a randomized controlled trial. Gut 2007; 56:545-552

62. Dite P, Ruzicka M, Zoril V, Novotny I. A prospective, randomized trial comparing endoscopic and surgical therapy for chronic pancreatitis. Endoscopy 2003;35:553-558.

63. Cahen DL, Gouma DJ, Nio Y, et al. Endoscopic versus surgical drainage of the pancreatic duct in chronic pancreatitis. N Eng J Med 2007;356:676-684

64. Myhre I, Hilstedt I, Troimier B, et al. Monitoring of celiac plexus block in chronic pancreatitis. Pain 1989;38:269-274

65. Puli SR, Reddy JBK, Bechtold ML, et al. EUS-guided celiac plexus neruolysis for pain due to chronic pancreatitis or pancreatic cancer pain. A meta-analysis and systematic review. Dig Di Sci 2009;54:23302337

66. Gress F, Schmitt C, Sherman S, et al. Endoscopic ultrasound-guided celiac plexus block for managing abdominal pain associated with chronic pancreatitis: A prospective single center experience. Am I Gastroenterol 2002;96:409-416

67. Buscher HCJL, Jansen JBMJ, van Dongen R, et al. Long-term results of bilateral thoracoscopic splanchnicectomy in patients with chronic pancreatitis. Br J Surg 2002;89:158-162.

68. Gould AP. Transaction of the Clinical Society of London. Lancet 1898:2:1532. 


\section{GUIDELINES}

69. Anderson AD, Frey CF. The evolution of the surgical treatment of chronic pancreatitis. Ann Surg 2010;25(1):18-32.

70. Diener MK, Rahbari NN, Fischer L, et al. Duodenum-preserving pancreatic head resection versus pancreatoduodenectomy for surgical treatment of chronic pancreatitis. A systematic review and metaanalysis. Ann Surg 2008;247(6):950-961.

71. Bachmann K, Kutup A, Mann O, et al. Surgical treatment in chronic pancreatitis timing and type of procedure. Best Pract Res Clin Gastroenterology 2010;24:299-310.

72. Diener MK, Bruckner T, Contin P, et al. ChroPac trial: Duodenum-preserving pancreatic head resection versus pancreatoduodenectomy for chronic pancreatitis. Trial protocol of a randomized controlled multicentre trial. Trials 2010;11:1-10

73. Saforafas GH, Sarr MG, Rowlands CM, et al. Post-obstructive chronic pancreatitis. Results with distal resection. Arch Surg 2001;136:643-647.

74. Howard TJ, Maiden CL Smith HG, et al. Surgical treatment of obstructive pancreatitis. Surg 1995;118:727-734.

75. Ong SL, Gravante G, Pollard CA, et al. Total pancreatectomy with islet auto-transplantation: an overview. HPB 2009;11:613-621.

76. Muller MW, Friess $\mathrm{H}$, Martin DJ, et al. Long-term follow-up of a randomized clinical trial comparing Beger with pylorus-preserving Whipple procedure for chronic pancreatitis. Br I Surg 2008;95:350-356. 77. Izbicki JR, Bloechle C, Broering DC, et al. Extended drainage versus resection in surgery for chronic pbicki $\mathrm{R}$, Bloechle $\mathrm{C}$, Broering $\mathrm{DC}$, et al. Extended drainage versus resection in surgery for chronic
pancreatitis: A prospective randomized trial comparing the longitudinal pancreaticojejunostomy pancreatitis: A prospective randomized trial comparing the longitudinal pancreaticojejunostomy
combined with local pancreatic head excision with the pylorus-preserving pancreatoduodenectomy. combined with local pancreatic head excision with the pylorus-preserving pancreatoduodenectomy. Ann Surg 1998;228

7. StrateT, Bachmann K, Busch P, et al. Resection vs drainage in treatment of chronic pancreatitis: longterm results of a randomized trial. Gastroenterology 2008;134:1406-1411.

7. Strate $\mathrm{T}$, Taherpour Z, Bloechle $\mathrm{C}$, et al. Long-term follow-up of a randomized trial comparing the Beger and Frey procedures for patients suffering from chronic pancreatitis. Ann Surg 2005;241:591-598.

80. Izbicki JR, Bloechle C, Broering DC, et al. Longitudinal V-shaped excision of the ventral pancreas for small duct disease in severe chronic pancreatitis. Prospective evaluation of a new surgical procedure. Ann Surg 1998;227(2):213-219.

81. Nealon WH, Walser E. Duct drainage alone is sufficient in the operative management of pancreatic pseudocysts in patients with chronic pancreatitis. Ann Surg 2003;237:614-620.
82. Van Loo ES, van Baal MCPM, Goozen HG, et al. Long-term quality of life after surgery for chronic pancreatitis. BJS 2010;97:1079-1086.

D'Egidio A, Schein M. Pancreatic pseudocysts: a proposed classification and its management implications. BJS 1991;78(8):981-984.

84. Apostolou C, Krige JEJ, Bornman PC. Pancreatic pseudocysts. South African Journal of Surgery 2006;44(4):148-154.

85. Beckingham IJ, Krige JEJ, Bornman PC, Terblanche J. Endoscopic management of pancreatic pseudocysts. Br J Surg 1997;84:1638-1645

6. Wiersma MJ. Endosonography-guided cyst-duodenostomy with therapeutic ultrasound endoscope. Gastrointest Endosc 1996;44:611-617.

87. Varadarajulu S, Lopes TL, Wilcox CM, et al. EUS versus surgical cyst-gastrostomy for management of pancreatic pseudocysts. Gastrointest Endosc 2008;68(4):649-655.

88. Park DH, Lee SS, Moon SY, et al. Endoscopic ultrasound-guide versus conventional transmural drainage for pancreatic pseudocysts: a prospective randomized trial. Endoscopy 2009;41:842-848.

89. Gomes-Cerezo J, Barbado Cano A, Suarez I, et al. Pancreatic ascites: study of therapeutic option by analysis of case reports and case series between the years 1975 and 2000. Am J Gastroenterol 2003;93(3):568-577.

90. Ganesh P, Suvrana D, Bhat G. Endoscopic treatment as first-line therapy for pancreatic ascites and pleural effusion. J Gastroenterol Hepatol 2009;24:1198-1202.

pleural effusion. J Gastroenterol Hepatol 2009;24:1198-1202.
1. Gallagher PI, McLauchlin G, Bornman PC, et al. Diagnostic pitfalls and therapeutic strategies in the treatment of pancreatic duct haemorrhage. HPB Surg 1997;10:293-297.

92. Abdallah A, Krige JEJ Bornman PC. Bile duct obstruction in chronic pancreatitis. HPB 2007:9:421428

93. Minghini A, Weireter L, Perry R. Specificity of elevated CA19-9 in chronic pancreatitis. Surgery 1998; 124:103-105.

94. Smith MD, Balabyeki MA, Leiman G, Wright CC. Prospective analysis of endoscopic brush cytology in pancreatico-biliary strictures. Journal of the Irish Colleges of Physicians and Surgeons 2002;31(2):77.

Accepted 27 September 2010. 
